NASA/TM-2004-212617

\title{
PIV Investigations of the Flow Field in the Volute of a Rotary Blood Pump
}

John M. Sankovic

Glenn Research Center, Cleveland, Ohio

Jaikrishnan R. Kadambi and Mehul Mehta

Case Western Reserve University, Cleveland, Ohio

William A. Smith

Cleveland Clinic Foundation, Cleveland, Ohio

Mark P. Wernet

Glenn Research Center, Cleveland, Ohio 
Since its founding, NASA has been dedicated to the advancement of aeronautics and space science. The NASA Scientific and Technical Information (STI) Program Office plays a key part in helping NASA maintain this important role.

The NASA STI Program Office is operated by Langley Research Center, the Lead Center for NASA's scientific and technical information. The NASA STI Program Office provides access to the NASA STI Database, the largest collection of aeronautical and space science STI in the world. The Program Office is also NASA's institutional mechanism for disseminating the results of its research and development activities. These results are published by NASA in the NASA STI Report Series, which includes the following report types:

- TECHNICAL PUBLICATION. Reports of completed research or a major significant phase of research that present the results of NASA programs and include extensive data or theoretical analysis. Includes compilations of significant scientific and technical data and information deemed to be of continuing reference value. NASA's counterpart of peerreviewed formal professional papers but has less stringent limitations on manuscript length and extent of graphic presentations.

- TECHNICAL MEMORANDUM. Scientific and technical findings that are preliminary or of specialized interest, e.g., quick release reports, working papers, and bibliographies that contain minimal annotation. Does not contain extensive analysis.

- CONTRACTOR REPORT. Scientific and technical findings by NASA-sponsored contractors and grantees.
- CONFERENCE PUBLICATION. Collected papers from scientific and technical conferences, symposia, seminars, or other meetings sponsored or cosponsored by NASA.

- SPECIAL PUBLICATION. Scientific, technical, or historical information from NASA programs, projects, and missions, often concerned with subjects having substantial public interest.

- TECHNICAL TRANSLATION. Englishlanguage translations of foreign scientific and technical material pertinent to NASA's mission.

Specialized services that complement the STI Program Office's diverse offerings include creating custom thesauri, building customized databases, organizing and publishing research results ... even providing videos.

For more information about the NASA STI Program Office, see the following:

- Access the NASA STI Program Home Page at http://www.sti.nasa.gov

- E-mail your question via the Internet to help@sti.nasa.gov

- Fax your question to the NASA Access Help Desk at 301-621-0134

- Telephone the NASA Access Help Desk at 301-621-0390

- Write to:

NASA Access Help Desk

NASA Center for AeroSpace Information 7121 Standard Drive

Hanover, MD 21076 
NASA/TM-2004-212617

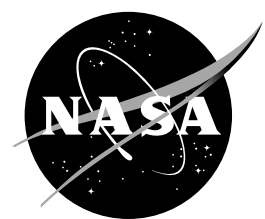

\section{PIV Investigations of the Flow Field in the Volute of a Rotary Blood Pump}

John M. Sankovic

Glenn Research Center, Cleveland, Ohio

Jaikrishnan R. Kadambi and Mehul Mehta

Case Western Reserve University, Cleveland, Ohio

William A. Smith

Cleveland Clinic Foundation, Cleveland, Ohio

Mark P. Wernet

Glenn Research Center, Cleveland, Ohio

Prepared for the

2003 Fluids Engineering Division Summer Meeting

cosponsored by the American Society of Mechanical Engineers

and the Japan Society of Mechanical Engineers

Honolulu, Hawaii, July 6-10, 2003

National Aeronautics and

Space Administration

Glenn Research Center 


\section{Acknowledgments}

The authors would like to acknowledge Jason Bradshaw and Sam Cordero, Case Western Reserve University, and Jonathan Rupp, Cornell University, for assistance in the development and fabrication of the acrylic pump.

Available from

NASA Center for Aerospace Information 7121 Standard Drive

Hanover, MD 21076
National Technical Information Service 5285 Port Royal Road Springfield, VA 22100 


\title{
PIV INVESTIGATIONS OF THE FLOW FIELD IN THE VOLUTE OF A ROTARY BLOOD PUMP
}

\author{
J.M. Sankovic \\ National Aeronautics and Space Administration \\ Glenn Research Center \\ Cleveland, Ohio \\ J.R. Kadambi and M. Mehta \\ Case Western Reserve University \\ Department of Mechanical and Aerospace Engineering \\ Cleveland, Ohio \\ W.A. Smith \\ The Cleveland Clinic Foundation \\ Department of Biomedical Engineering \\ Cleveland, Ohio \\ M.P. Wernet \\ National Aeronautics and Space Administration \\ Glenn Research Center \\ Cleveland, Ohio
}

\begin{abstract}
A full-size acrylic model of a rotary blood pump was developed in order to utilize Particle Image Velocimetry (PIV) to make measurements of the fluid velocities and turbulent stresses throughout the device. The development of an understanding of the hemodynamics within the blood pump is critical to the development and validation of computational models. A blood analog solution, consisting of sodium iodide solution and glycerin, was developed to match physiological kinematic viscosity. The refractive indecies of the fluid, the pump casing and the impeller were matched to facilitate the use of PIV to make velocity measurements. Velocity measurements made in the volute exit/diffuser region are presented for pumps speeds of 3000-3850 rpm. At each speed data were obtained at a physiological pressure of $90 \mathrm{mmHg}$ and at a maximum flow condition. Four hundred data pairs were used for each resultant mean velocity vector value, representing greater than an order of magnitude more data pairs than reported previously in the literature on similar devices and resulting in velocity uncertainty levels of approximately $\pm 2.9 \%$.
\end{abstract}

\section{INTRODUCTION}

Mechanical assistance in blood pumping varies widely depending on the application. For example hundreds of thousands of open-heart surgeries are performed in the US yearly, and in those cases the patient is placed on a blood pump along with an oxygenator. The duration of use of this type of blood pump is limited to hours and beyond the concern for hemolysis and thrombosis, the engineering constraints, although difficult, are not nearly as challenging as for the incorporeal applications. Incorporeal applications or so-called artificial heart applications are extremely challenging. Not only must the device not cause hemolysis and thrombosis, but also the reliability must be high, the power consumption low, and the package size must be compact.

The predominant current uses of mechanical circulatory support devices are as a bridge to transplantation and to provide temporary pumping assistance after cardiac surgery in cases where the heart tissue needs to have the pumping work load removed to allow for healing. In the US approximately 6000 receive support devices after cardiac surgery with a survival rate of $20-40 \%$ in the hospital. Bridging for transplantation occurs in 300-400 patients yearly with a discharge rate of $50-70 \%$ after transplantation. Regarding the devices, several factors are not yet clear: 1) the need for biventricular versus univentricular support, 2) a total artificial heart versus a ventricular assist device, and 3 ) the duration of 
support is not defined and depends on donor organ availability, time to myocardial recovery, potential outpatient therapy, and unpredictability of adverse events regarding the new technology (Stevenson and Kormos 2000).

One of the major advantages of a rotary pump over pulsatile technology is the reduced physical pump volume. Pulsatility requires $80-140$ beats $/ \mathrm{min}$ to generate a flow rate of $8 \mathrm{l} / \mathrm{min}$, hence the pumping volume is over $60 \mathrm{ml} / \mathrm{stroke}$. This makes reducing an implantable pulsatile pump below $400 \mathrm{ml}$ very difficult. Rotary pumps also do not require a volume shifting compliance chamber, which increases pulsatile pumps by an additional $100 \mathrm{ml}$. Increasing the rotary pump's speed allows shrinking of the volume, with volumes below $20 \mathrm{ml}$ demonstrated. Rotary pumps can be designed to occupy one-tenth the volume of a pulsatile pump, allowing the insertion of the pump inside the existing left ventricle. Even as late as 1992 many doubted that a rotary implantable blood pump could be developed. Thrombus formation at and near the shaft of the impeller support was considered a life-limiting mechanism. Additionally, the control was thought to be very difficult. Due to the advantages of a rotary pump over a pulsatile pump several researchers pursued the technology and by 1995 the technology looked very promising (Nosé 1995).

When compared to industrial pumps, blood pumps operate in a unique flow regime. The Reynolds number (based on the impeller diameter, is on the order of $10^{4}$. This is on the low end of commercial pumps, which have focused mainly on the high end of the Reynolds number range of $2 \times 10^{4}$ to $10^{8}$, since the hydraulic losses increase dramatically below a knee at $\mathrm{Re}=1 \times 10^{5}$ (Soundranayagam and Ramarajan (1986)). Sparse literature exists in the high loss regime of blood pump operation. To complicate matters further, blood is a dense, high particle concentration, solid-liquid slurry, which exhibits non-Newtonian characteristics at low shear rates. Gopalakrishnan [1999] presents an excellent overview of US pump research and development. In regard to hydraulics, flow field modeling has progressed greatly. Two decades ago, Gopalakrishnan (1981) used a NASA meridional plane method (Katsanis (1964)) to model basic flow in an impeller. At that time no viscous terms were included, hence losses were based on assumptions and slip was estimated using empirical coefficients. Presently, commercial codes such as TASCflow have become popular for pump simulation. These code have also been used for blood pump simulations (Apel, et al.
(2001)) The codes solve Reynolds Stress Averaged Navier-Stokes (RANS) equations. Turbulence models are usually based on simple k- $\varepsilon$ models and log-wall functions are used to simulate boundary layers.

Gopalakrishnan (1999) summarizes the state-of-art of pump CFD, "While CFD holds the promise of becoming a useful tool for pump design, it must be noted that a major unknown in fluid dynamics today is a realistic model for turbulence...pump designers will use some of the existing turbulence models and calibrate their CFD results against test data thereby introducing some empiricism into their analysis." The need for experimental flow field data is still necessary for industrial pump model development and validation. For blood pumps, with their extremely complex flow regime, the need is even greater. Obtaining information across the entire flow field can be extremely laborious. Particle image velocimetry (PIV) has the advantage of providing instantaneous velocity information over an entire plane. An excellent overview of the technique is provided by Raffel et al. (1998).

Several researchers have applied PIV to the study of rotary pumps. Dong, et al. (1992) used PIV in a $25.4 \mathrm{~cm}$ diameter; $890 \mathrm{rpm}$ pump. The flow regime was inertially dominant with water as the working fluid and the use of acrylic pump parts. Fluorescent particles were used with an autocorrelation technique. The technique uses a laser light sheet to illuminate particles in the flow. Double exposures recorded on a single image can be auto-correlated to obtain velocity information since the time between light source pulses is known. One drawback of the auto-correlation technique is that direction is not known. This can be overcome by obtaining pairs of single exposure images and using a cross-correlation technique, as has been used to study complex flows in the Laser Flow Diagnostics Laboratory at Case Western Reserve University (Kadambi, et al. (2003)). Dong, et al. found that the flow was pulsating and depended on the location of the blade relative to tongue. Sites prone to high velocity fluctuations included blade wake, interface between the jet and the wake, and near the tongue. A follow-on study by Chu, et al. (1995) used the same set-up as Dong, et al. The paper did not mention the number of sets of data averaged for turbulence measurements; however, $35 \mathrm{~mm}$ film was used for data collection making data reduction of multiple sets arduous. That study found that slight increases in the space between impeller and tongue caused significant changes in flow structure. The 
impact was significant as long as the gap was less than $20 \%$ of impeller radius. Large vortex trains associated with jet/wake phenomena dominated variations in total pressure. A more recent study by Sinha and Katz (2000) reported the inclusion of digital data acquisition with the same pump hardware. They discuss the issues of the commonly used RANS in commercial CFD codes, including the validity of turbulence closure.

Attempts at using several flow visualization techniques for artificial organs have been reported in the literature. Particle streak imaging using fluorescence was used by Kerrigan, et al. (1994) in the Nimbus Axipump and by Kerrigan, et al. (1996) in a prototype SUN Medical Technology pump. Laser Doppler anemometry (LDA) has been used successfully to obtain velocity information on the popular BP-80 by Pinotti and Paone (1996); however, the technique is limited to instantaneous point measurement. Particle Tracking was reported by Sakuma, et al. $(1995,1996)$ and by Asztalos, et al. (1999). Asztalos, et al. used a 3x scale pump operating at $126 \mathrm{rpm}$ and $9 \mathrm{l} / \mathrm{min}$, which corresponded to a full scale pump operating at $1,900 \mathrm{rpm}$ and $5 \mathrm{l} / \mathrm{min}$. A 256 × 256 bit 4500 frame/s camera was used, with no image-to-image variance or turbulence data reported. Subramanian, et al. (2000) applied PIV to the study of heart valves and Wernet, et al. (2001) compared the advantages of PIV with respect to LDA as applied to heart valves. Mussivand, et al. (1999) applied PIV to a HeartSaver pulsatile VAD by using a $300 \mathrm{~W}$ halogen lamp and camera with frame rate of $1000 / \mathrm{s}$, but was limited to $100-200$ micron diameter particles due to the light source. That paper reported Reynolds shear stresses (RSS) based on the measured instantaneous velocity fluctuation using a 25 velocity data point ensemble in $5 \mathrm{~mm}$ region to obtain the mean velocity. No estimate of uncertainty was presented. Peak RSS levels of $>9000$ dynes $/ \mathrm{cm}^{2}$ reported. Day, et al. (2001) have applied PIV to investigate the gap between housing and rotor centrifugal blood pump manufactured by HeartQuest/MedQuest Products Inc. pump. The velocities presented in that work were the average of 20 image pairs. Most recently Day, et al. (2002) have reported recent progress in applying PIV to an acrylic model of the HeartQuest pump and have presented velocity field data for the pump inlet; however, no mention is made regarding number of data pairs or the measurement uncertainty.

The ability to obtain an instantaneous 2-D view of a time varying flow field makes PIV an extremely powerful experimental tool. Existing PIV data in the literature for blood pumps, either makes no mention of uncertainty or is the average of less than 25 image pairs, which are far too few for sufficient estimate of the mean velocity and turbulence characteristics of the flow field. Furthermore, blood is a high-density slurry of flexible particles, with a nominal biconcave disk geometry. Limited studies of commercial slurry pumps demonstrate that the flow fields can be significantly impacted by reasonable particle concentrations.

Because of the difficulties associated with measurements in solid-liquid slurry flow in pumps only a few experimental studies are available in the open literature with a detailed literature review provided by Charoennegam (2001). Kadambi, et al. (2000) discussed the development of a refractive index matched slurry pump loop to investigate slurry flow in pumps using PIV and presented single-phase flow results. Kadambi, et al. (2002) used the same slurry loop and PIV to conduct experiments using 500 micron glass beads at volumetric concentrations of $2.5 \%$ and $5 \%$ to study flow in the tongue region. In that study it was observed that the particle fluctuation kinetic energy increased approximately $200 \%$ to $500 \%$ as the pump speed was increased from $725 \mathrm{rpm}$ to $1000 \mathrm{rpm}$. The directional impingement mechanism is quite significant in the tongue and the casing regions. Most recently Kadambi, et al. (2003) used this slurry flow loop to investigate flow of $2.5 \%$ and $5 \%$ volumetric particle concentrations in the impeller blade passages.

The overall goal of our work is to obtain experimental measurements of the flow field throughout a rotary blood pump with high enough fidelity to allow the development and validation of computational design tools. The initial results of that effort are presented herein and include the development of an optically clear rotary blood pump test-bed and measurements of the velocities and turbulent shear stress in the volute exit and diffuser at various operating conditions.

\section{EXPERIMENTAL APPARATUS AND PROCEDURE}

\section{Pump and flow loop}

In order to enable the use of PIV for all areas of the pump, the pump housing, and impeller were fabricated from acrylic as shown in Figure 1. The pump housing was fabricated in two sections, which bisected the volute and diffuser. The pump design had heritage to those reported previously by Bernstein, et al. (1974), Golding and Smith (1996), and Veres, et al. (1997). 
The nominal design operation condition for the pump was $5 \mathrm{l} / \mathrm{min}$ at a pressure rise of $100 \mathrm{mmHg}$ and a speed of $3000 \mathrm{rpm}$. The impeller consisted of seven straight blades which are offset from the centerline with an outside diameter of $35 \mathrm{~mm}$. The impeller described by Golding and Smith and Veres, et al., consisted of an open center section, where the blades were mounted on a ring and a stationary center shroud provided a gradual transition from the axial flow near the inlet to the radial impeller flow. To facilitate fabrication, the impeller used in this study had a solid center section that incorporated the center shroud with the ring holding the blades.

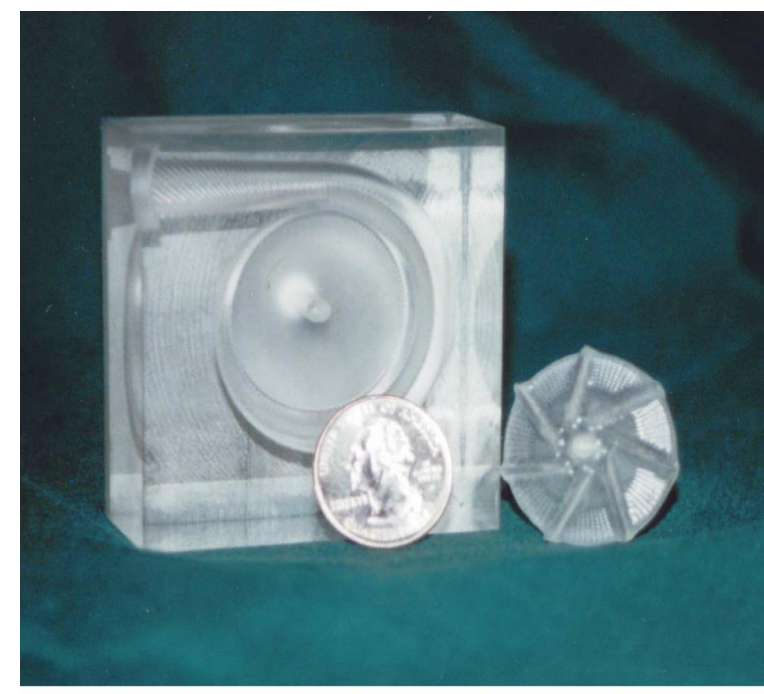

Figure 1.-Impeller and casing of acrylic model of blood pump

The working fluid used for this study was a mixture of water, sodium iodide and glycerin. The sodium iodide/water solution was selected such that the refractive index of acrylic was matched, and was measured to be $1.485 \pm 0.001$. Silver-coated glass spheres, 15 micron in diameter were used as the particles and were neutrally buoyant. The pump design and operating conditions were chosen to maintain similarity with those reported earlier. The geometry was maintained at actual scale and the speed range was duplicated. In order to maintain Reynolds number similarity, glycerin was used to increase the viscosity of the fluid such that the kinematic viscosity of the fluid was similar to that of blood. In this case, the measured kinematic viscosity was $3.2 \mathrm{cS}$.

The flow loop consisted of a reservoir, which was open to atmosphere, to which a $13 \mathrm{~mm}$ ID inlet tube was connected. The height of the fluid in the reservoir was equal to the height of the discharge. After passing through the pump, the fluid passed through an exit tube also with a $13 \mathrm{~mm}$ ID and returned to the supply reservoir. The pump pressure rise was measured by the use of a simple manometer located downstream of the diffuser. Flow regulation was accomplished by the use of a pinch clamp valve located at the exit tube near the discharge to the fluid reservoir.

The flow rate was calibrated by fixing both the output pressure of the pump and speed, and then measuring the volume of fluid pumped for a set time interval. Calibration was performed using the sodium iodide solution. This measurement was taken over the entire range of operating conditions. Performance curves of the pump are presented in Figure 2. The data shows that the achieved flow rates at a given speed are lower than those reported by Golding and Smith (1996). It is believed that the inlet and outlet fittings used in this study contributed an increased pressure drop not seen in the published results, and caused a decrease in flow. Further improvements in the transition from the pump to the test loop should decrease these effects.

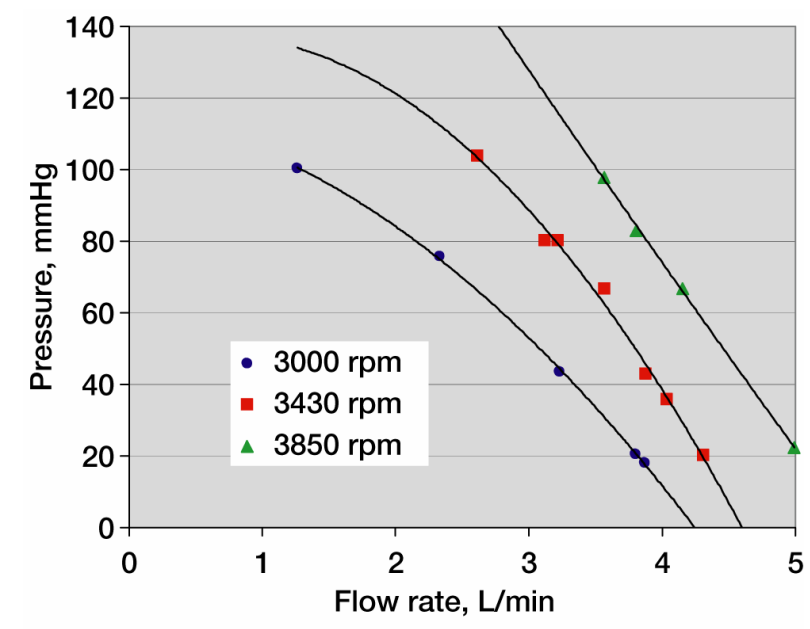

Figure 2.-Pressure-flow curves for pump operating at various speeds utilizing sodium iodide solution.

\section{PIV System}

The PIV set-up was similar to that used by Kadambi, et al (2003). The PIV hardware consists of a 50 $\mathrm{mJ} /$ pulse Nd:YAG laser (532 $\mathrm{nm}$ wavelength), laser light sheet optics, a CCD camera (Dantec DoubleImage 700 cross-correlation camera; resolution: $768 \times 484$ pixels) equipped with a $60 \mathrm{~mm}$ Micro Nikkor lens (Nikon). The laser beam (3.5 mm diameter) is formed into a light sheet $(0.37 \mathrm{~mm}$ thick; $256 \mathrm{~mm}$ wide) using a combination of cylindrical and spherical lenses. In order to eliminate distortion at the pump housing seam, the light sheet was aligned 
parallel to the seam and passed entirely through the half containing the inlet section. For each of the operating conditions 400 pairs of single exposure image frames were obtained and analyzed using crosscorrelation data processing. The image pairs are processed into vector maps, in real-time, by the Dantec FlowMap PIV 2000 processor. The image pair acquisition was synchronized to the impeller rotation using a once per rev signal, which then triggered the digital delay generator (DDG). The DDG in turn sent a signal to the PIV 2000 processor, which then fired the laser and acquires the images from the PIV camera. Figure 3 shows a schematic diagram of the PIV setup.

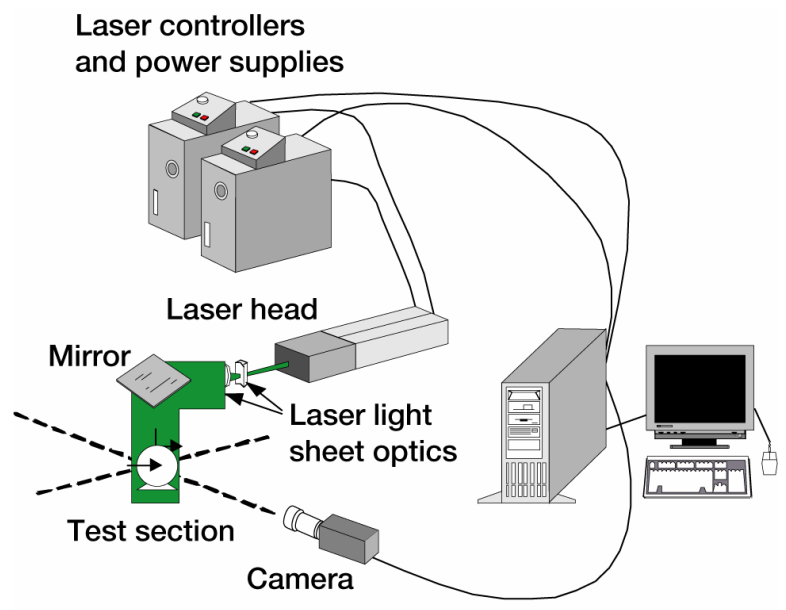

Figure 3.-Schematic diagram of PIV experimental set-up.

The camera lens is operated at $\mathrm{f} / \# 8$ and the field of view (FOV) was 24.1 x $17.8 \mathrm{~mm}$. Images were analyzed using a subregion size of $32 \times 32$ pixels with $50 \%$ overlap. This resulted in $47 \times 29$ vectors in the FOV with a spatial resolution of $0.51 \times 0.61 \mathrm{~mm} /$ vector. The FOV included both the volute exit/diffuser and the inter-blade region; however, large differences in velocity in those regions precluded the use of a $32 \times 32$ subregion size across the entire FOV. This was due to the fact that the hardware was constrained at the lower level of time between laser pulses. Analysis of the higher velocity flow in the inter-blade region was limited to a 64 x 64 pixel subregion size in order to not have the particles travel farther than 0.25 of the subregion dimension between the image pairs.

Data reported herein consists of 18 x 29 vectors representing the volute exit/diffuser region. Post- processing of the data was performed on the 400 image pairs to determine mean velocities and relative uncertainties to a $95 \%$ confidence level and RSS levels. Chauvenet's criterion was used to remove spurious points during analysis.

\section{RESULTS AND DISCUSSION}

Data were obtained at three rotational speeds of 3000 , 3430 , and $3850 \mathrm{rpm}$. In addition at each speed, two pump operating points were investigated. The first condition sought to maintain a constant output pressure of $90 \mathrm{mmHg}$ to simulate a physiologically relevant condition: $1.8,3.0$, and $3.71 / \mathrm{min}$ at 3000 , 3430 , and $3850 \mathrm{rpm}$, respectively. This was accomplished via adjustment of the downstream tube clamp, which served as a flow restriction. The second operating point was the maximum flow condition for that speed: $4.0 \quad 1 / \mathrm{min} \quad(11.6 \mathrm{mmHg}), 4.4 \quad 1 / \mathrm{min}$ $(14.0 \mathrm{mmHg})$ and $5.1 \mathrm{l} / \mathrm{min}(15.8 \mathrm{mmHg})$ at 3000 , 3430 , and $3850 \mathrm{rpm}$, respectively. It is believed that those two conditions would be representative of the high pressure differential/lower flow region and the low pressure differential/high flow region of the pump pressure/flow curve. Using the 400 data pairs, the average over the $18 \times 29$ vector matrix of the uncertainty in the mean velocity ranged between $2.4 \%$ and $2.9 \%$, which includes uncertainty estimates for both random and bias effects.

A sample PIV image is presented as Figure 4 in order to illustrate the coordinate system used and the orientation of blades. All data were obtained with one blade perpendicular to the cutwater as shown in Figure 4.

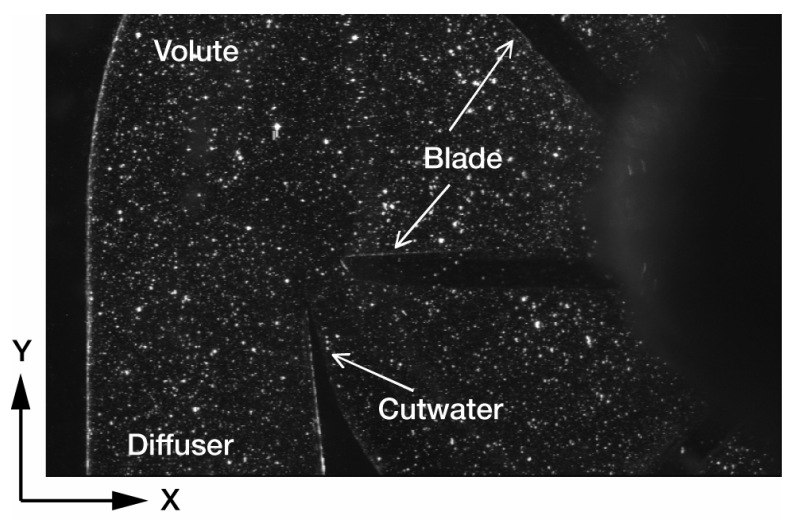

Figure 4.-Sample PIV image showing impeller blade position, volute exit and diffuser. 
Figure 5 provides velocity vector plots in the volute/diffuser region for maximum flow conditions for the three speeds. Variations in velocity magnitude are presented as color variations in the figure. What is evident is the influence of the cutwater (tongue) on the velocity profile and the boundary layer growth on the wall immediately opposite of the cutwater as the flow is slowed. Although the magnitude of the velocity vectors increase with rotational speed as expected, the vector angles also appear similar. This point was investigated more fully by looking at the velocity vectors at a Y location of $16.5 \mathrm{~mm}$. At that horizontal location the flow conditions are both influenced by the incoming volute flow (from the top of Figure 4 and the additional mass from the blade passage (from the right of Figure 4). Figure 6 provides plots of the velocity vector angle relative to the vertical and the magnitude of the velocity normalized to the tip speed. The figure shows that over an axial position of 3.5 to $9.0 \mathrm{~mm}$ the velocity vectors scale directly with tip speed. This leads to the prediction that the velocity triangles are similar for the three flow conditions. Direct measurements in the inter-blade region will serve to validate that hypothesis.

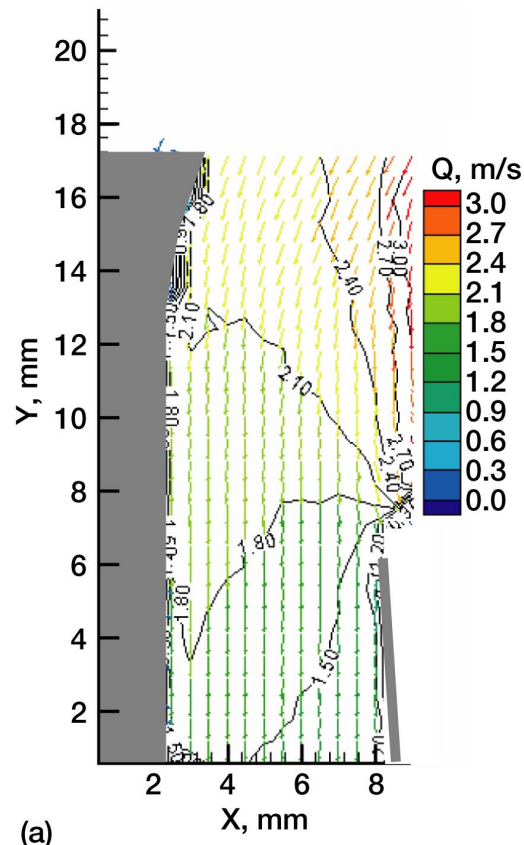

(a)

Figure 5.-Velocity vector maps of volute exit and diff
condition. (a) $3000 \mathrm{rpm}$. (b) $3430 \mathrm{rpm}$. (c) $3850 \mathrm{rpm}$.

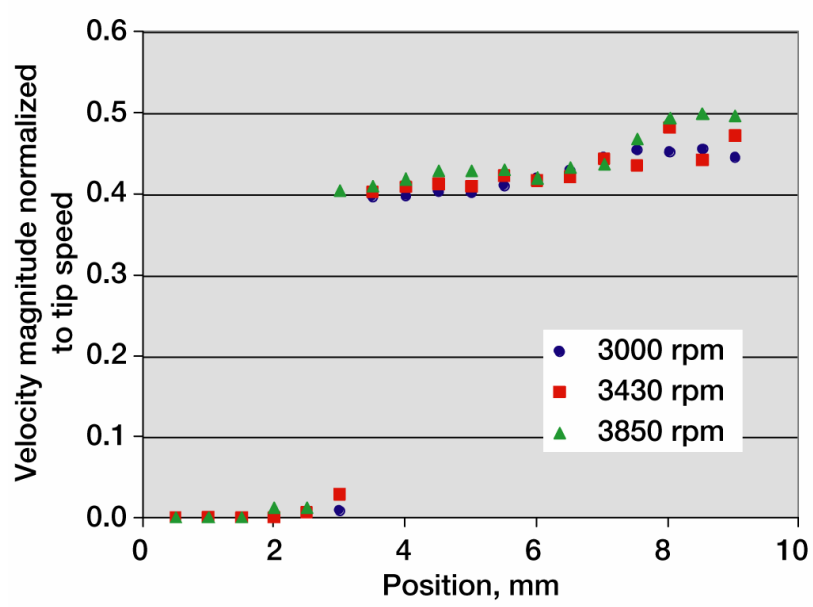

(b)
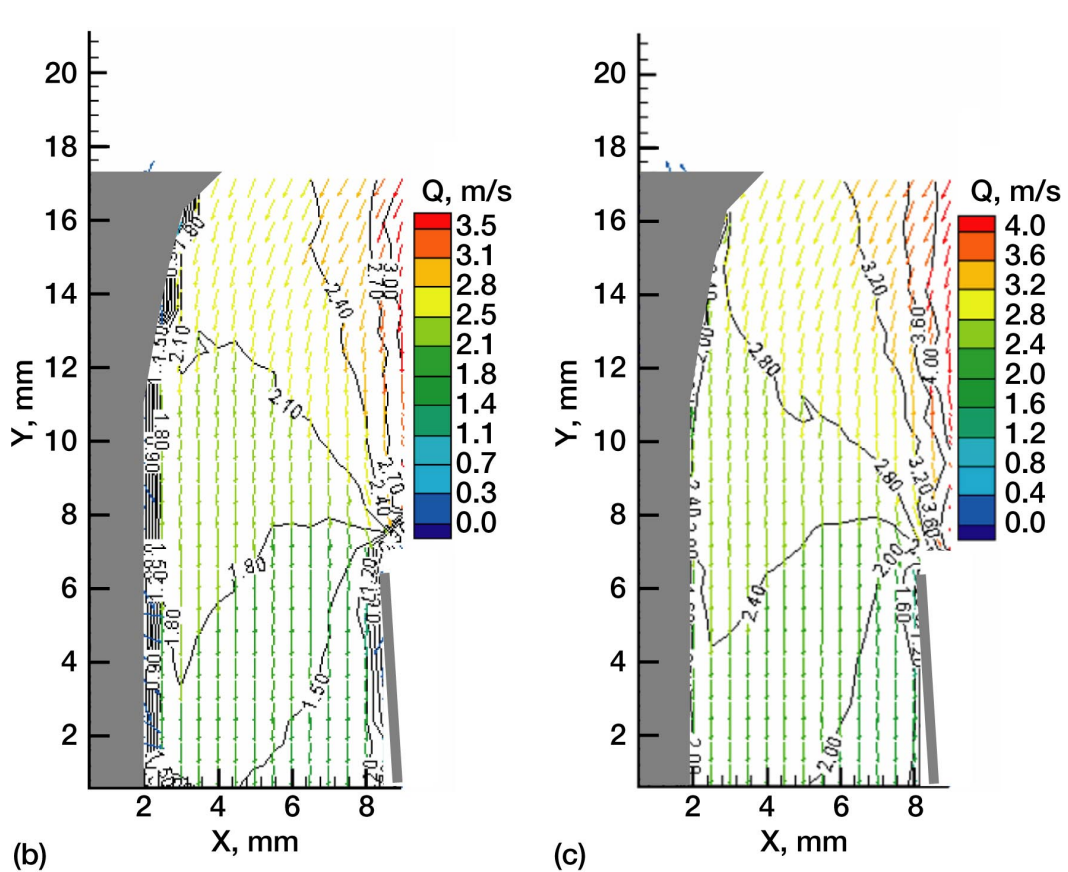

(c)

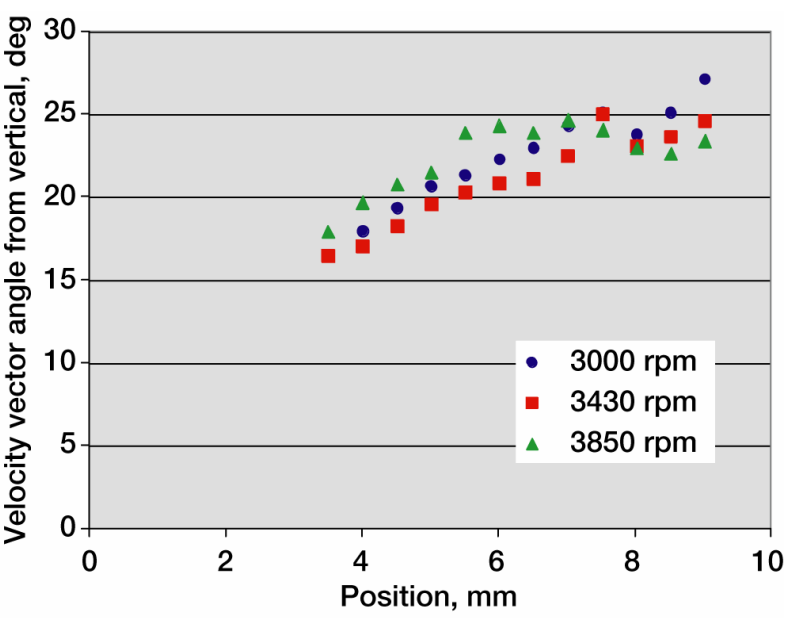

Figure 6.-Similarity of velocity vectors at various points across the volute at location $\mathrm{Y}=16.5 \mathrm{~mm}$. (a) Velocity magnitude normalized to tip speed. (b) Velocity vector angle relative to diffuser axis. 

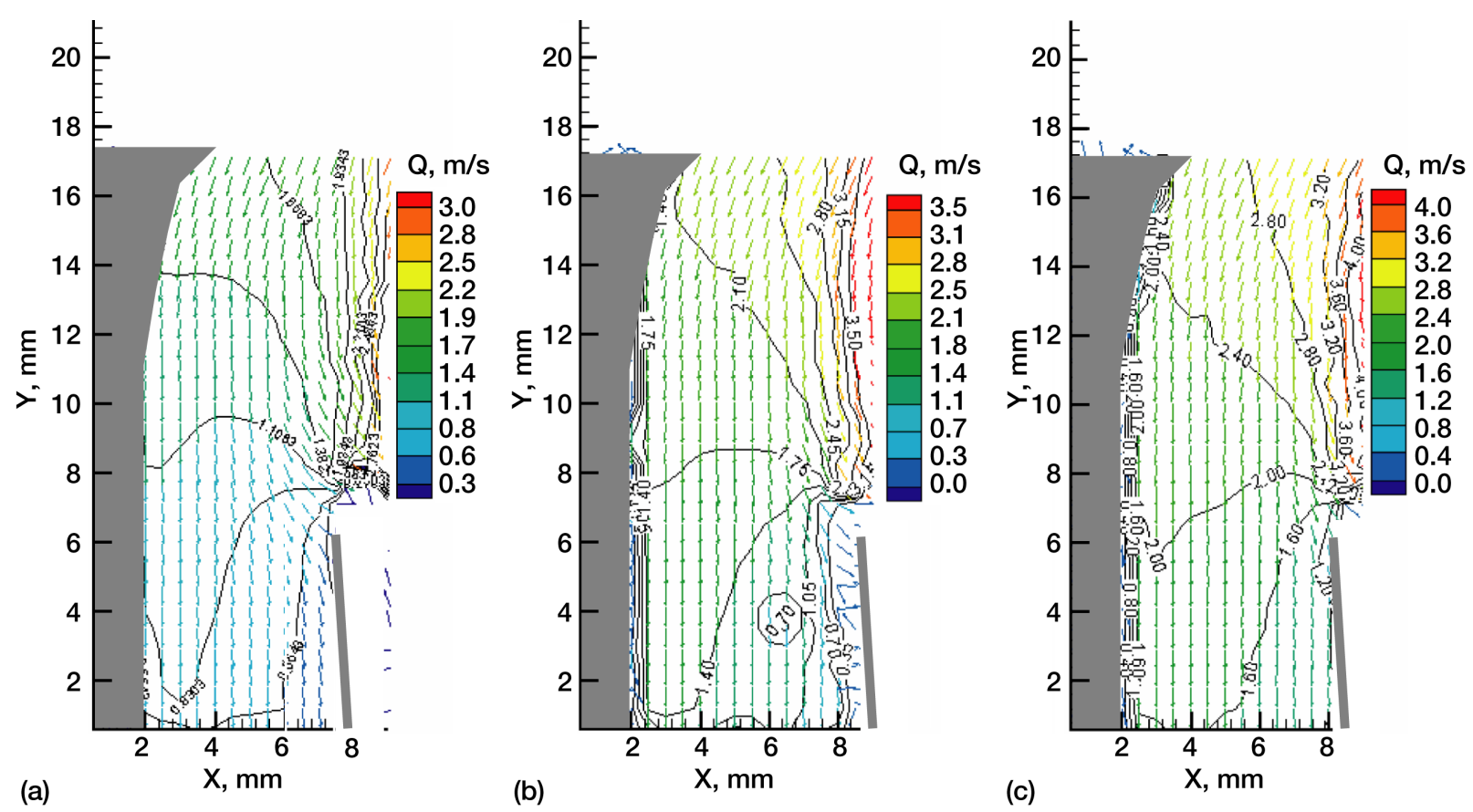

Figure 7.-Velocity vector maps of volute exit and diffuser region at various impeller speeds at $90 \mathrm{mmHg}$ pressure rise. (a) $3000 \mathrm{rpm}$. (b) $3430 \mathrm{rpm}$. (c) $3850 \mathrm{rpm}$.

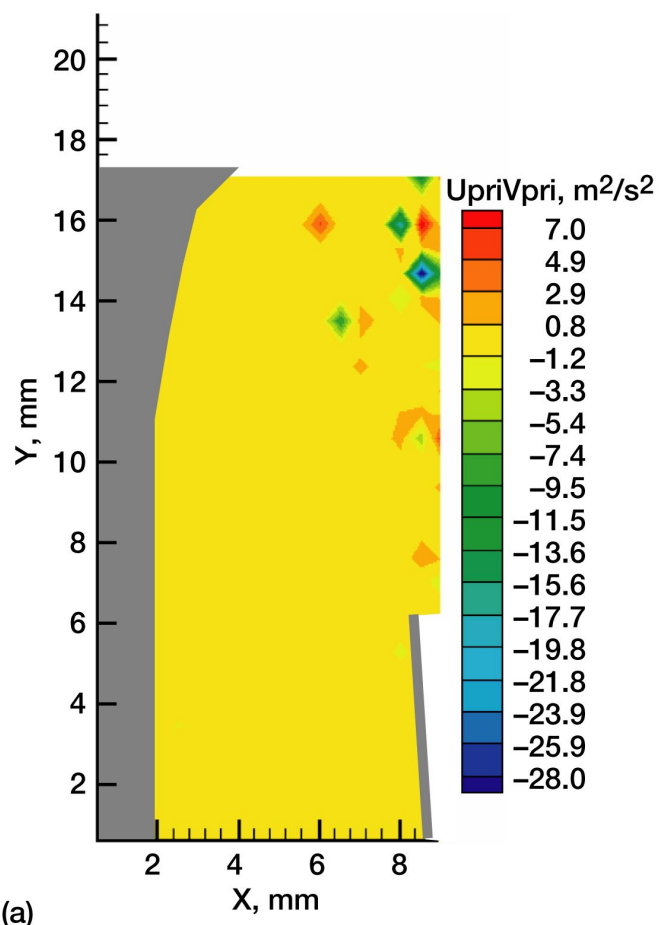

(a)

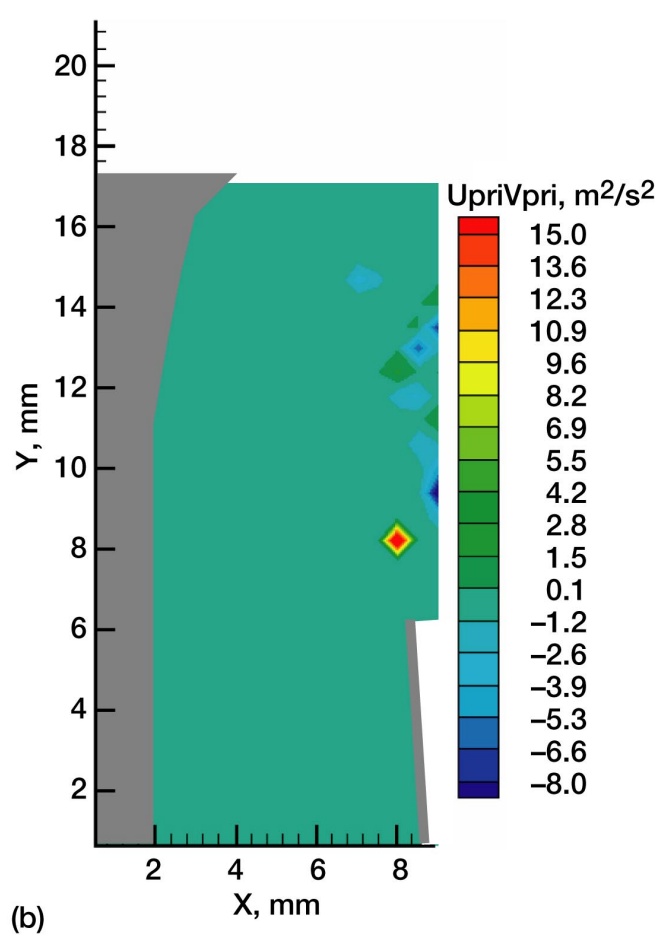

Figure 8.-Reynolds shear stress levels depicted as mean u'v' (m²/s²). (a) $3850 \mathrm{rpm}$; 5.11/min/15.8 mmHg.

(b) $3000 \mathrm{rpm} ; 1.81 / \mathrm{min} / 90 \mathrm{mmHg}$.

Figure 7 provides related velocity vector plots for the three speeds at a constant pressure of $90 \mathrm{mmHg}$. Again, variations in velocity magnitude are presented as color variations in the figure. The flow rates for these operating conditions were significantly lower than the data sets presented in the previous section. In this flow regime recirculation losses are important. The $3000 \mathrm{rpm}$ data clearly shows the flow reentering 
the impeller passage upstream of the cutwater. This flow is essentially repumped causing the losses to multiply. Also, of interest is that the trajectory of the particles is such that significant impingement may occur on the cutwater surface, which could be of significance for cell-wall energy transfer effects. As the speed increases from 3000 to 3430 , and finally to $3850 \mathrm{rpm}$, the operating point moves in the direction of the best efficiency point. Since the pressure is being held constant, it would be expected that the losses would decrease. As shown in Figure 7 the entrainment of the flow steadily decreases as the speed (and hence volumetric flow) increases, signifying a decrease in recirculation losses.

Knowledge of the shear stresses in the flow field of a blood pump is of critical importance. Often in blood pump literature, little attention is paid to the RSS caused by turbulence in the flow. The use of PIV offers a powerful tool to obtain direct measurements of the turbulence level of the flow and a measurement of the RSS from the mean of u'v'.

Figure 8 shows a color contour plot of u'v' $\left(\mathrm{m}^{2} / \mathrm{s}^{2}\right)$ for the volute/diffuser region for the highest flow rate tested $5.1 \mathrm{l} / \mathrm{min}$ at $(3850 \mathrm{rpm}$ and an outlet pressure of $15.8 \mathrm{mmHg}$ ). Using the fluid density of $1.69 \mathrm{~kg} / \mathrm{m}^{3}$, the RSS was calculated to reach $47 \mathrm{kPa}$ and occurred at the exit of the blade passage $8 \mathrm{~mm}$ upstream of the cutwater. Looking at the other extreme in flow conditions, the minimum flow case of $1.8 \mathrm{l} / \mathrm{min}$, which occurred at a speed of $3000 \mathrm{rpm}$ and a pressure of $90 \mathrm{mmHg}$, the highest RSS occurred immediately upstream of the cutwater, with the majority of the area investigated steady. The results show that significant turbulent stresses can be present in a rotary blood pump and warrant further investigation utilizing a higher resolution.

\section{CONCLUDING REMARKS}

The development of efficient and reliable rotary blood pumps that do not cause hemolysis and thrombosis is a significant engineering challenge. As the technology advances, so does the need for engineering tools such as computational modeling. Particle image velocimetry offers a powerful experimental method to develop an understanding of the flow field in order to develop and validate such models. This work presented the results of the initial phase of obtaining experimental measurements throughout a rotary blood pump. Measurements in the volute exit/diffuser section were obtained at pumps speeds ranging from
3000 to $3850 \mathrm{rpm}$. Over the range of operating conditions tested, various flow phenomena were noted. At the extreme operating condition of $90 \mathrm{mmHg}$ and $1.8 \mathrm{l} / \mathrm{min}$, significant reentry of the flow back into the impeller was observed, signifying increased recirculation losses. At the opposite extreme of $15.8 \mathrm{mmHg}$ and $5.1 \mathrm{l} / \mathrm{min}$, the influence of the cutwater is evident. In addition at the maximum flow conditions the velocity vectors in the volute scaled directly with impeller tip speed over the entire speed range. Reynolds shear stress measurements showed regions of significant stress levels that warrant further investigation.

\section{REFERENCES}

Antaki JF, Ghattas O, Burgreen GW, He B., (1995) "Computational flow optimization of rotary blood pump components," Artif Organs, 19(7):608-615.

Apel J, Paul R, Klaus S, Siess T, Reul H (2001) "Assessment of hemolysis related quantities in a microaxial blood pump by computational fluid dynamics." Artif Organs, 25(5):341-7.

Asztalos B, Yamane T, Nishida M. (1999), "Flow visualization analysis for evaluation of shear and recirculation in a new closed-type, monopivot centrifugal blood pump." Artif Organs, 23(10):939-46.

Bernstein EF, Cosentino LC, Reich S, Stasz P, Levine ID, Scott DR, Dorman FD, Blackshear PL Jr. (1974) "A compact, low hemolysis, non-thrombogenic system for non-thoracotomy prolonged left ventricular bypass." Trans Am Soc Artif Intern Organs, 20 B: 643-52.

Chu, S., Dong, R., Katz J., (1995) "Relationship between unsteady flow, pressure fluctuations, and noise in a centrifugal pump-part A: use of PDV data to compute the pressure field," Journal of Fluids Engineering, Transactions of the ASME Vol. 117, pp. 24-29.

Day SW, McDaniel JC, Wood HG, Allaire PE, Landrot N, Curtas A. (2001) "Particle image velocimetry measurements of blood velocity in a continuous flow ventricular assist device." ASAIO J Jul-Aug;47(4):406-11

Day, S.W., McDaniel, J.C., Wood, H.G., Allaire, P.E., Song, X., Lemire, P.P., and Miles, S.D., (2002) "A Prototype HeartQuest Ventricular Assist Device for Particle Image Velocimetry Measurements," Artificial Organs, 26(11): 1002-1005. 
Dong, R., Chu, S., and Katz, J., (1992) A. quantitative visualization of the flow within the volute of a centrifugal pump. part a: technique. J. Fluids Engineering, vol. 114, pp. 390-395.

Dong, R., Chu, S., and Katz, J., (1992)b. Quantitative visualization of the flow within the volute of a centrifugal pump. part b: results and analysis. J. Fluids Engineering, vol. 114, pp. 396-403.

Golding LA, Smith WA.(1996) "Cleveland Clinic rotodynamic pump." Ann Thorac Surg, Jan; 61 (1): 457-62.

Gopalakrishnan, S. (1981) "Computer based hydraulic design of pumps," 7th Technical Conference of the British Pump Manufacturer's Association, York, England.

Gopalakrishnan, S., "Pump research and development: past, present, and future- an American perspective" (1999) Journal of Fluids Engineering, Vol. 121, no. 2, pp. 237-247.

Katsanis (1964) "Use of arbitary quasi orthogonals for calculating flow distribution in the meridional plane of a turbomachine," NASA TN D-2546.

Kadambi, J.R., Addie, G., Subramanian, A., Mahiwan, (2000). "PIV Investigations of Flow in a Centrifugal Slurry Pump", 9th International Symposium on Flow Visualization, Edinburgh, Scotland, September 22-26.

Kadambi J.R, Charoenngam P, Sankovic J, Wernet M, Addie G, Subramanian A, Courtwright R (2002) "PIV investigations of particle velocities in the tongue regions of a slurry pump" Proceedings of the 2002 ASME Fluids Engineering Division Summer Meeting, Montreal, Canada, July 14-18.

Kadambi, J.R., Mehta, M., Charoenngam, P., Wernet, M., Sankovic, J., and Addie, A. (2003) "Particulate velocity measurements in the intra-blade passages of a centrifugal slurry pump" FEDSM2003-45504, Proceedings of the 2003 ASME Fluids Engineering Division Summer Meeting, Honolulu, Hawaii, July 6-10.

Kerrigan JP, Shaffer FD, Maher TR, Dennis TJ, Borovetz HS, Antaki JF. (1993) "Fluorescent image tracking velocimetry of the Nimbus AxiPump." ASAIO J Jul-Sep; 39 (3): M639-43.

Kerrigan JP, Yamazaki K, Meyer RK, Mori T, Otake Y, Outa E, Umezu M, Borovetz HS, Kormos RL, Griffith BP, Koyanagi H, Antaki JF. (1996)" Highresolution fluorescent particle-tracking flow visualization within an intraventricular axial flow left ventricular assist device." Artif Organs Jun; 20 (6): 534-40.

Mussivand T, Day KD, Naber BC. (1999) "Fluid dynamic optimization of a ventricular assist device using particle image velocimetry." ASAIO J. Jan-Feb; 45(1):25-31.

Nosé, Y. (1995) "Can we develop a totally implantable rotary blood pump?," Artif. Org, 19 (7): 561-562.

Pinotti M and Paone N. (1996)" Estimating mechanical blood trauma in a centrifugal blood pump: laser Doppler anemometer measurements of the mean velocity field.“ Artif Organs Jun; 20 (6): 546-52.

Raffel, M., Willert, C.E., and Kompenhaus, J., (1998) Particle Image Velocimetry: A Practical Guide, Springer-Verlag.

Sakuma I, Tadokoro H, Fukui Y, Dohi T. (1995) "Flow visualization study on centrifugal blood pump using a high speed video camera." Artif Organs, Jul; 19 (7): 665-70.

Sakuma I, Fukui Y, Dohi T. (1996) "Study of secondary flow in centrifugal blood pumps using a flow visualization method with a high-speed video camera." Artif Organs, Jun; 20 (6): 541-5.

Sinha, M. and Katz, J. (2000) "Quantitative visualization of the flow in a centrifugal pump with diffuser vanes-1: on flow structures and turbulence," Journal of Fluids Engineering, Vol. 122, pp. 997-107.

Soundranayagam, S. and Ramarajan, V. (1986) "Scale effects in a mixed flow pump: part 2," Proc Instn Mech Engrs, Vol. 200 No A3, 180-186.

Stevenson LW, Kormos RL. (2001) "Mechanical Cardiac Support 2000: Current applications and future trial design." J Thorac Cardiovasc Surg, Mar; 121 (3): 418-24.

Subramanian A, Mu H, Kadambi JR, Wernet MP, Brendzel AM, Harasaki H. (2000) "Particle image velocimetry investigation of intravalvular flow fields of a bileaflet mechanical heart valve in a pulsatile flow," J Heart Valve Dis, Sep;9 (5): 721-31.

Veres JP, Golding LA, Smith WA, Horvath D, Medvedev A. (1997) "Flow analysis of the Cleveland Clinic centrifugal pump.” ASAIO J., Sep-Oct; 43 (5): M778-81.

Wernet MP, Subramanian A, Mu H, Kadambi JR. (2000) "Comparison of particle image velocimetry and laser Doppler anemometry measurements in turbulent fluid flow."Ann Biomed Eng, 28 (11): 1393-6. 


\begin{tabular}{|c|c|c|c|}
\hline \multicolumn{3}{|c|}{ REPORT DOCUMENTATION PAGE } & $\begin{array}{l}\text { Form Approved } \\
\text { OMB No. 0704-0188 }\end{array}$ \\
\hline \multicolumn{4}{|c|}{$\begin{array}{l}\text { Public reporting burden for this collection of information is estimated to average } 1 \text { hour per response, including the time for reviewing instructions, searching existing data sources, } \\
\text { gathering and maintaining the data needed, and completing and reviewing the collection of information. Send comments regarding this burden estimate or any other aspect of this } \\
\text { collection of information, including suggestions for reducing this burden, to Washington Headquarters Services, Directorate for Information Operations and Reports, } 1215 \text { Jefferson } \\
\text { Davis Highway, Suite 1204, Arlington, VA 22202-4302, and to the Office of Management and Budget, Paperwork Reduction Project (0704-0188), Washington, DC 20503. }\end{array}$} \\
\hline 1. AGENCY USE ONLY (Leave blank) & $\begin{array}{l}\text { 2. REPORT DATE } \\
\text { February } 2004\end{array}$ & 3. REPORT TYPE A & $\begin{array}{l}\text { ID DATES COVERED } \\
\text { echnical Memorandum }\end{array}$ \\
\hline $\begin{array}{l}\text { 4. TITLE AND SUBTITLE } \\
\text { PIV Investigations of the Fla }\end{array}$ & \multicolumn{2}{|c|}{ PIV Investigations of the Flow Field in the Volute of a Rotary Blood Pump } & 5. FUNDING NUMBERS \\
\hline \multicolumn{4}{|c|}{$\begin{array}{l}\text { 6. AUTHOR(S) } \\
\text { John M. Sankovic, Jaikrishnan R. Kadambi, Mehul Mehta, William A. Smith, } \\
\text { and Mark P. Wernet }\end{array}$} \\
\hline $\begin{array}{l}\text { 9. SPONSORING/MONITORING AGEI } \\
\text { National Aeronautics and Sp } \\
\text { Washington, DC } 20546-00\end{array}$ & $\begin{array}{l}\text { NAME(S) AND ADDRESS(E } \\
\text { Administration }\end{array}$ & & $\begin{array}{l}\text { 10. SPONSORING/MONITORING } \\
\text { AGENCY REPORT NUMBER } \\
\text { NASA TM - 2004-212617 } \\
\text { FEDSM2003-45490 }\end{array}$ \\
\hline \multicolumn{4}{|c|}{$\begin{array}{l}\text { 11. SUPPLEMENTARY NOTES } \\
\text { Prepared for the } 2003 \text { Fluids Engineering Division Summer Meeting cosponsored by the American Society of Mechanical } \\
\text { Engineers and the Japan Society of Mechanical Engineers, Honolulu, Hawaii, July 6-10, 2003. John M. Sankovic and } \\
\text { Mark P. Wernet, NASA Glenn Research Center; Jaikrishnan R. Kadambi and Mehul Mehta, Case Western Reserve } \\
\text { University, Cleveland, Ohio 44106; and William A. Smith, Cleveland Clinic Foundation, Cleveland, Ohio } 44106 . \\
\text { Responsible person, John M. Sankovic, organization code 6712, 216-977-7429. }\end{array}$} \\
\hline
\end{tabular}

\section{ABSTRACT (Maximum 200 words)}

A full-size acrylic model of a rotary blood pump was developed in order to utilize Particle Image Velocimetry (PIV) to make measurements of the fluid velocities and turbulent stresses throughout the device. The development of an understanding of the hemodynamics within the blood pump is critical to the development and validation of computational models. A blood analog solution, consisting of sodium iodide solution and glycerin, was developed to match physiological kinematic viscosity. The refractive indices of the fluid, the pump casing, and the impeller were matched to facilitate the use of PIV to make velocity measurements. Velocity measurements made in the volute exit/diffuser region are presented for pumps speeds of 3000 to $3850 \mathrm{rpm}$. At each speed, data were obtained at a physiological pressure of $90 \mathrm{mmHg}$ and at a maximum flow condition. Four hundred data pairs were used for each resultant mean velocity vector value, representing greater than an order of magnitude more data pairs than reported previously in the literature on similar devices and resulting in velocity uncertainty levels of approximately \pm 2.9 percent.

\begin{tabular}{|c|c|c|c|}
\hline 14. SUBJECT TERMS & & & $\begin{array}{c}\text { 15. NUMBER OF PAGES } \\
15\end{array}$ \\
\hline SN 7540-01-280-5500 & & & $\begin{array}{l}\text { ndard Form } 298 \text { (Rev. 2-89) } \\
\text { cribed by ANSI Std. Z39-18 } \\
102\end{array}$ \\
\hline
\end{tabular}

